\title{
Enterprise Mashup Systems as Platform for Situational Applications
}

\section{Benefits and Challenges in the Business Domain}

\author{
Currently, several Enterprise 2.0 platforms are beginning to emerge. This new generation
} of web-based enterprise platforms significantly influences application development and use. Apart from the IT department, the end users participate in the development of business applications by composing their own work environments based on their continuously changing needs. This paper introduces Enterprise Mashup technology as a means to improve IT alignment of individual work processes and changing business needs. Furthermore, organizational key drivers, technical challenges and inhibitors are discussed to assess the potential business value and explain the emerging expansion of Mashup platforms in companies.

\section{The Authors \\ Dipl. Wirtsch. Inf. Immanuel Pahlke ( $\varangle)$ Dipl. Wirtsch. Inf. Martin Wolf Chair of Business Administration esp. Information Systems Goethe University Frankfurt Grüneburgplatz 1 60323 Frankfurt (Main) Germany pahlke@wiwi.uni-frankfurt.de mwolf@wiwi.uni-frankfurt.de}

Prof. Dr. Roman Beck Chair of Business Administration esp. E-Finance and Services Science Goethe University Frankfurt Grüneburgplatz 1 60323 Frankfurt (Main) Germany rbeck@wiwi.uni-frankfurt.de

Received: 2009-11-30 Accepted: 2010-05-29 Accepted after two revisions by Prof. Dr. Buhl.

Published online: 2010-08-27
This article is also available in German in print and via http://www. wirtschaftsinformatik.de: Pahlke I, Beck R, Wolf M (2010) EnterpriseMashup-Systeme als Plattform für situative Anwendungen. Nutzen und Herausforderungen für Unternehmen. WIRTSCHAFTSINFORMATIK. doi: 10.1007/s11576-010-0240-4.

(c) Gabler Verlag 2010

\section{Motivation}

In recent years, enterprises have optimized their IT portfolio by adopting modular service-oriented architectures and process-oriented approaches. At the same time, the emergence of the Web 2.0 paradigm as well as the dissemination of semantic web standards has opened up new and innovative ways for mass collaboration, personalization and creation of user-generated content (Kim et al. 2009). Thus, the Web has evolved from a unidirectional to a participatory, bilateral platform providing services intertwined with their respective data. The emerging technology of Mashup systems extends this paradigm by enabling knowledge workers to go beyond static publishing fos- tering the creation of customized, situational applications ${ }^{1}$ through the combination of web-enabled, third party resources in a dynamic way. Increasingly, enterprises are now taking Enterprise Mashup (EM) technology seriously. For instance, market research companies like Gartner (2008) and Forester (Young et al. 2008) confirm a high economical significance of EM and forecast a growing relevance of this paradigm in the coming years. Furthermore, recent scientific work also emphasizes the importance of Mashup platforms as an extension of enterprise integration infrastructures and a supplement to service-oriented business architectures and classical business intelligence platforms (see, e.g., Bitzer and Schumann 2009; Gamble and Gamble 2008). However, the business impact of Mashup introduction has not yet been analyzed adequately since existing research mainly focuses on the underlying technical concepts and principles of Mashup systems (Maximilien et al. 2008; Rosenberg et al. 2009), i.e., the design stage (Hoyer et al. 2008; Koschmider et al. 2009) and implementation (Blake 2009; Yu et al. 2008; Vancea et al. 2008). Therefore, both the benefits and the challenges on an enterprise level will be addressed in this paper in order to evaluate the potential of service-oriented and flexible

\footnotetext{
1"Situational" in terms of rapidly created or contextually customized to address immediate need of an individual or a community (Balasubramaniam et al. 2008, p. 50).
} 
Table 1 Journals and conferences investigated for the literature review

\begin{tabular}{ll}
\hline Publication type & Journals/Conferences \\
\hline Journals & ACMSIG, CACM, CAIS, CompDcsn, DATABASE, DSI, DSS, EJIS, I\&M, I\&O, IBMSJ, IEEEComp, IEEESw, IEEEIC, IEEETC, \\
& IEEETKDE, IEEETrans, IEEETSE, IEEETSMC, IJEC, IJHCS, InfoSys, ISF, ISJ, ISM, ISR, IT\&M, IT\&P, JACM, JAIS, JCIS, \\
& JComp, JCSS, JIM, JITTA, JMIS, JSIS, KBS, MISQ, MS, SMR, WIRT \\
Conferences & AMCIS, ECIS, ICIS, HICSS, IEEE Conferences, LNCS, MKWI, PACIS, WI \\
\hline
\end{tabular}

collaboration technologies like Mashup platforms for the business domain.

The remainder of this article is organized as follows: Sect. 2 describes the methodological approach of our literature review which forms the theoretical foundation. Due to the heterogeneous research implications and ambiguous perception of EMs, Sect. 3 provides a theoretically grounded definition of EM systems and a description of the architectural and organizational elements involved. Furthermore, core design principles and important aspects of the organizational assimilation of EM systems are presented. Section 4 elaborates on the business drivers and benefits as well as the risks and further challenges of the EM technology for companies. In addition, the prerequisites in order to (technically) facilitate the deployment in a company are described. Section 5 concludes the paper with final remarks and suggests future research directions.

\section{Methodology}

In order to describe, synthesize, evaluate, and integrate the results of extant scientific work on EM platforms, we conducted a literature review following the approach of Webster and Watson (2002). This research method ensures that an extensive number of relevant papers are considered.

The first step in the literature selection process was conducted to identify a comprehensive list of literature sources. We started off by taking the top journals based on the VHB-JOURQUAL2 (Schrader and Hennig-Thurau 2009) and Saunders's (2010) journal ranking. From both lists, only journals that had published papers dealing with our research topic were taken into consideration. In total, we selected 43 leading management information systems journals. In addition, we reviewed the proceedings of major international conferences considered important for our analysis to include the analysis of even very recent research. Table 1 lists all literature sources that were examined to identify relevant papers.

In a subsequent step, we chose topicrelated papers from the selected literature sources. An initial list of papers was generated by using key words such as "mashup", "enterprise mashup", "business mashup", "situational application", "composite application" and "user generated application" to search for titles, abstracts, and keywords. We only scanned the directories of the journals and conference proceedings manually if no electronic search was possible. Furthermore, we expanded our scientific foundation by reviewing the citations in the identified papers in the first literature exploration cycle to determine prior papers that should be considered for analysis in a subsequent literature exploration cycle. We identified 96 papers all dealing with EMs or at least containing related keywords. In order to indentify the final set of publications we subjected these papers to a more detailed (contentrelated) review. Therefore, we manually reviewed the papers of the initial list and select only those papers which primarily deal with EMs. Those 35 papers are listed in Table 2. In order to provide an overview of the related content, we assigned the objectives and the applied methodology to these papers. It is surprising that almost the entire set of the finally selected papers consists of conference papers and there are only very little high-quality journal papers. This probably shows that EMs and related topics are so far under-researched. However, it seems that both, practitioner and theoreticians are interested in EM technologies and related benefits in the business domain.

\section{A Conceptual Perspective on Enterprise Mashups}

The concept of EMs integrates Web 2.0 technologies and principles with wellestablished paradigms like enterprise information integration (EII), business intelligence (BI), and business process management (BPM) (de Vrieze et al. 2009, p. 68; Simmen et al. 2008, p. 1181). In this section, different forms of Mashup platforms are delineated, a common definition of EMs is derived, and the architecture of the overarching EM environment is described.

\subsection{Classification and Definition of Enterprise Mashups}

In extant literature, terms like "Enterprise Mashups", "Business Mashups", and “Composite Applications” (Keyser 2007) are used interchangeably but are often defined at different levels. Based on our literature review and an analysis of the functionality of existing implementations, we have developed a classification of EM types as illustrated in Table 3 where we categorize four different types of EMs according to complexity. The classification ranges from plain integration implementations at the front end (presentation level) to more complex platforms which provide process orchestration capabilities and therefore allow business users to automate work processes (process level).

A presentation Enterprise Mashup focuses on retrieving information and layout from different sources, without integrating data and application functionality (Daniel et al. 2007). Pre-built components are simply combined by drag-anddrop operations in a graphical user interface. An example for such an EM tool is Dapper. ${ }^{2}$ This tool allows users to simply drag and drop pre-built components into a common user interface and subsequently to reuse and share the results. Data Enterprise Mashups are restricted to

${ }^{2}$ http://www.dapper.net/technology.php (2010-03-20). 


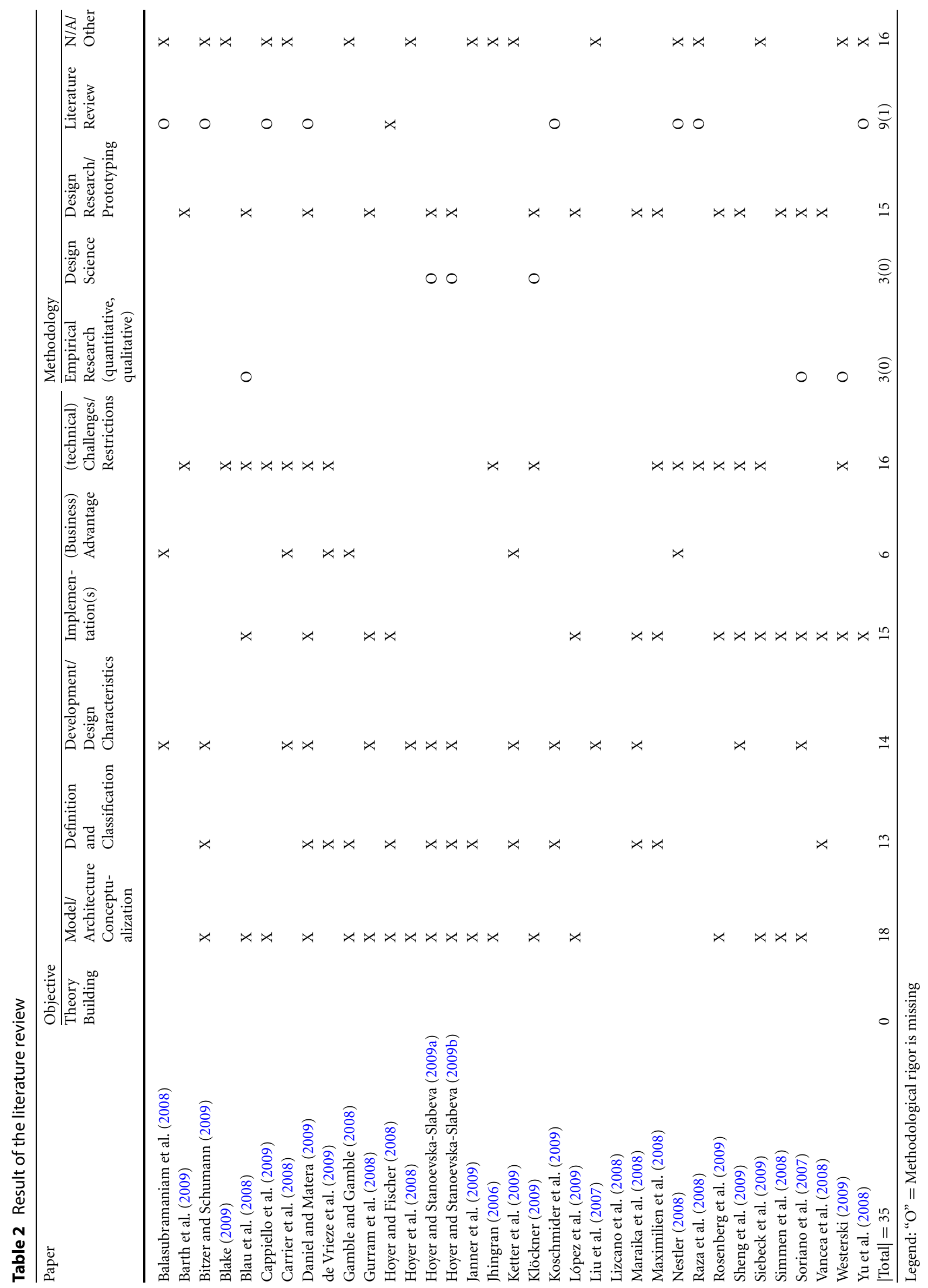


Table 3 Types of Enterprise Mashup systems (based on de Vrieze et al. 2009, pp. 65-66; Koschmider et al. 2009, pp. 2-3)

\begin{tabular}{lll}
\hline EM types & Description & Complexity \\
\hline Presentation & Focus on retrieving information and layout from disparate sources & Simple \\
Data & Combine, manipulate, and integrate disparate information services to present a unified view \\
Functionality & Combine and integrate information and application functionality services provided by different & \\
& sources & Integrate and orchestrate information services, business functionality services according to a \\
Process & business/work processes sequence & Complex \\
&
\end{tabular}

integrating data and information services from different sources and presenting the results in a unified view (Westerski 2009), e.g., by overlaying sales data on a map and pairing inventory data with customer orders to present a unified and intuitive view of, for example, product shortage in different subsidiaries. ARIS MashZone from IDS Scheer, ${ }^{3}$ IBM Mashup Center, ${ }^{4}$ Convertigo Enterprise Mashup Studio ${ }^{5}$ or PRESTO from $\mathrm{JackBe}^{6}$ are commercial examples of this EM type. They are primarily meant for ad hoc business analysis resulting from the combination of internal data with publicly available information. Functionality-oriented Enterprise Mashups empower the users to combine and integrate any kind of components (e.g. information or business application services) via generic interfaces. Nevertheless, in a business context even more complex EM platforms that facilitate the orchestration of information and business application services according to a process sequence will prevail (Koschmider et al. 2009, p. 3). Processoriented Enterprise Mashups thereby focus on user interface (UI) integration (Daniel et al. 2007) by combining process orientation with elements from end userdriven application development as well as end user participation (Lieberman et al. 2006). According to the information provided by the vendors of EM platforms such as Serena Business Mashup Suite "SBM" or Enterprise Mashup Solutions from Lixto, ${ }^{8}$ they fulfill these functionalities. Therefore, these platforms consider the integration of data resources, (web) services and business processes to one common representation.

Accordingly, we extend the definition of Hoyer and Fischer (2008, p. 710) by emphasizing the interaction between business process actors to ground this paper on consistent and comprehensive EM terminology. We define EM platforms as systems that combine existing resources, e.g., data application functionality or services from more than one source in enterprise environments by empowering business users to create and adapt individual information, centric and situational applications as well as invoking business logic across multiple business process actors (applications, services, and employees).

\subsection{Schematic Architecture of Enterprise Mashup Environments}

Due to the lack of a single, commonly accepted conceptualization of Mashup architectures, this paper elaborates on characteristics and corresponding architectural elements of EM environments. The major architectural elements of EM systems are summarized in Table 4.

EM environments need to provide easy integration of existing EM components as well as an efficient allocation of EM components. Therefore, an EM development cycle should focus on the discovery and sharing of mashable components as the core elements of the development process by enabling the reuse of existing resources in new combinations (Carrier et al. 2008, pp. 10-18; Ketter et al. 2009).

Figure 1 summarizes this conceptualization with regard to the involved actors and their roles in the development and allocation process. On the lowest layer, the external and internal resources are located. Standardized interfaces abstract these resources from their technical implementation and facilitate the loose coupling of different resources fulfilling a central requirement of service-oriented architectures (High et al. 2008). These resources are provided by internal developers or offered by external vendors. As the central entity, the resources are accessed via application programming interfaces (APIs) like Really Simple Syndication (RSS), Web Services Description Language (WSDL), Representational State Transfer (REST) etc. (Bitzer and Schumann 2009, p. 6; Yu et al. 2008, p. 48). The mediator virtualizes the resources through generic APIs or UIs and integrates different resources into usable and shareable components. Functional requirements such as the need for end user-friendly interfaces, a standardized API, and compatible data formats for easy integration have to be taken into account (Cappiello et al. 2009, pp. 237, 238). The objective is to provide additional graphical and simple user interaction mechanism abstracting from the underlying resources and the corresponding technical interfaces (Hoyer and Stanoevska-Slabeva 2009a, p. 4).

On the highest level of abstraction, knowledge workers create, adopt, use and share EM applications. They facilitate the adding and removing of pre-built components as well as accessible services and other resources, e.g., by linking welldefined input and output ports with a graphical development tool and therefore personalizing their work environments to fulfill individual, situational business needs (López et al. 2009; Simmen et al. 2008, p. 1173).

\subsection{Design of Enterprise Mashups}

In order to understand EMs from a design perspective, the following subsection

\footnotetext{
$\overline{{ }^{3} \mathrm{http} / / / w w w . i d s}$-scheer.de/de/ARIS/ARIS_Innovationen/ARIS_MashZone/151359.html (2010-03-20).

${ }^{4} \mathrm{http}: / / \mathrm{www}-142 . \mathrm{ibm} . \mathrm{com} / \mathrm{software} /$ products//us/en/mashupcenter (2010-03-20).

${ }^{5} \mathrm{http}: / /$ www.convertigo.com (2010-03-20).

${ }^{6} \mathrm{http}: / /$ www.jackbe.com/Products/ (2010-03-20).

${ }^{7} \mathrm{http}: / /$ www.serena.com/products/sbm/ (2010-03-20).

${ }^{8} \mathrm{http} / / /$ www.lixto.com/technology_product_summary/ (2010-03-20).
} 
Table 4 Components of Enterprise Mashup architectures (based on, e.g., Carrier et al. 2008, p. 6; Hoyer and Fischer 2008, p. 710; Ketter et al. 2009, p. 294)

\begin{tabular}{lll}
\hline Elements & Description & Other Terms \\
\hline Resource & $\begin{array}{l}\text { Content, data and functionality resources (services) which are accessible through established but } \\
\text { specific APIs } \\
\text { Virtualized components that can be easily “mashed” through generic APIs or UIs }\end{array}$ & Asset \\
Component & A lightweight application combining components from different sources & Mashlet, \\
Widget or Gadget & Mashup \\
EM application & Technology that provides the functionality to create, deploy, modify, and share EM applications & EM system \\
EM environment & Includes the technical platform as well as the organizational structures and actors & -
\end{tabular}

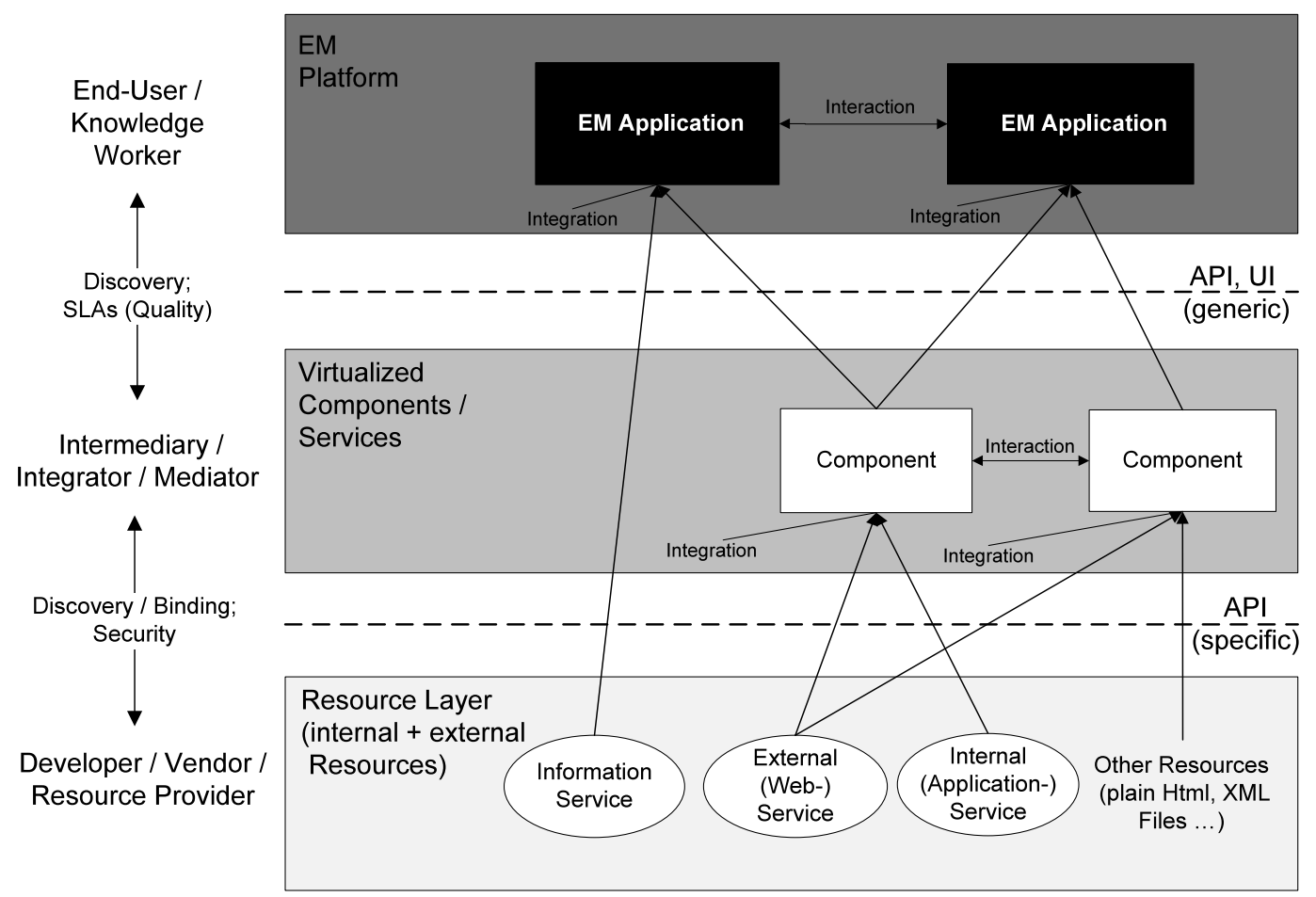

Fig. 1 The Enterprise Mashup environment (based on, e.g., Gurram et al. 2008; Hoyer and Stanoevska-Slabeva 2009a; Lizcano et al. 2008; Soriano et al. 2007)

deals with the major design characteristics of Mashup applications with regard to the combination of Web 2.0 concepts and the service-orientation paradigm that materialize on the individual level of analysis.

\subsubsection{Lightweight Orchestration and Composition}

EMs are intended to address user needs that might arise spontaneously in the form of situational applications which provide a flexible response to a changing business environment (Liu et al. 2007). Therefore, one of the central design principles of EMs is the lightweight resource composition concept which is reflected by the reuse of existing building blocks (components) in different contexts (Hoyer and Stanoevska-Slabeva 2009a, p. 4; Janner et al. 2009, p. 977; Ketter et al. 2009, p. 259). The term "lightweight" is used to refer to orchestration that is based on open standards (platform independency) and does not require the allocation of native resources in the operating system.

Regarding the different elements of EM architecture (see Table 4), the composition involves both the resource layer and the component or services layer (Hoyer et al. 2008, p. 10). Thus, EMs represent the fusion of two converging principles: service-orientation and the Web 2.0 paradigm (Janner et al. 2009, p. 977; Nestler 2008, p. 551).

\subsubsection{Emergence of Component Intermediaries}

The effective implementation of market mechanisms for the allocation of application services and data resources requires overcoming still remaining economic and technical challenges (Blau et al. 2008). In addition, the variety of business user requirements and the diversity of computational services on the provider side are further challenging the discovery, allocation, and use of appropriate services (Borissov et al. 2009). Consequently, the role of the IT de- 
partment is changing from that of a traditional service provider to one of a service-mediating entity. Furthermore, novel forms of (external) intermediaries are about to emerge which provide a resource directory and extend the role of the traditional UDDI-based implementations in terms of, for example, the quality of services (QoS) and security (Hoyer and Stanoevska-Slabeva 2009a, p. 4). After initial publication by the resource owner, advanced intermediaries continuously monitor the current status of the resource (such as the availability and latency) and provide performance metrics which empower potential customers to select an appropriate resource (Schroth and Christ 2007).

\subsubsection{Developing Enterprise Mashup Applications}

Since traditional software engineering approaches are not appropriate for efficiently supporting the highly dynamic EM development process, new software engineering approaches have emerged (Hoyer et al. 2008; Ketter et al. 2009; Yu et al. 2008). A comparison of development process characteristics is provided in Table 5.

The development process is characterized by an agile, non-formal, iterative, and collaborative development model focusing on the actual IT artifact and not on a comprehensive specification or documentation (Janner et al. 2009 p. 976; Ketter et al. 2009, p. 293; Cherbakov et al. 2007). In addition, the development lifecycle emphasizes operational utilization as an integral part of the development process allowing for continuous and incremental improvement and adaptation of the deployed EM solution (Duvall et al.
2007). The objective of this new development approach is to integrate end users from business units, who often possess only marginal technical skills in the software development process (Cherbakov et al. 2007; Ketter et al. 2009, p. 293). Therefore, the core of this new software engineering approach encompasses two aspects (Hoyer and Stanoevska-Slabeva 2009a): first, the empowerment of business users to satisfy ad hoc needs by the reuse and combination of existing components, and second, a broad involvement of business users drawing on the peer production concept (Benkler 2006). Both aforementioned aspects are presented in the following section.

\subsection{Business User Participation and Mashup Communities}

The EM paradigm can be used to implement a business user innovation concept by leveraging the collective knowledge and productivity. Business users are actively involved in the creation of Mashup applications and thus are part of a technologically induced process of organizational decentralization (von Hippel 2005).

The broad involvement of users can be based on the peer production principle. According to Benkler (2006, p. 62), who coined the term "peer production", "it refers to production systems that depend on individual action that is self-selected and decentralized rather than hierarchically assigned". Thereby, the creative energy of a large number of people, often referred to as the "Wisdom of Crowds", could be used to aggregate knowledge and abilities in groups (Surowiecki 2004).

As a prerequisite, the process of selecting relevant services and components should be supported. Besides default semantic annotations (functional and nonfunctional characteristics) created by resource providers, a "tagging mechanism" could enable business users to categorize components. These user-rating functionalities based on popularity and relevance are utilized to collect, distribute, and aggregate feedback about the features of resource (López et al. 2009, p. 37; Hoyer and Stanoevska-Slabeva 2009a, p. 4).

Furthermore, business users have to be empowered to provide their own EMs to other groups within the same community or company (Lizcano et al. 2008, p. 17). As soon as components and Mashup applications are available, they can be reused or improved by colleagues without any involvement from the IT department. The sharing of knowledge within a community is therefore considered to be a key driver for EMs (Hoyer and Stanoevska-Slabeva 2009b, p. 9).

\section{Evaluation of Mashup Technology in the Business Domain}

The business interest in EM systems is driven by potential benefits based on increased employee productivity, higher flexibility or individuality and usability of individual work processes (e.g., Ketter et al. 2009, p. 294). EMs enable business users to participate in the information and business functionality creation process by empowering them to integrate internal and external data with business functionality in a cooperative manner themselves. Automating manual and repetitive operations and work processes as well as the sharing of business knowledge are further business benefits

Table 5 Comparison of development process characteristics (based on Carrier et al. 2008, p. 5)

\begin{tabular}{|c|c|c|c|}
\hline & & EM & Traditional \\
\hline \multirow[t]{2}{*}{ Scope } & Development time & Days to weeks & Weeks to years \\
\hline & Lifespan & Variable, often short & Long life \\
\hline \multirow[t]{3}{*}{ Process } & Development phases & Ad-hoc, trial and error & (Strictly) defined, scheduled \\
\hline & Governance & Decentralized, community & Formal, centralized \\
\hline & Evolution & Organic & Top-down, centrally driven \\
\hline \multirow[t]{2}{*}{ Developer/User } & Application builder & $\begin{array}{l}\text { Line of business, } \\
\text { individuals or groups }\end{array}$ & Special IT department developers \\
\hline & Target user & $\begin{array}{l}\text { Small teams or } \\
\text { individuals }\end{array}$ & Large groups \\
\hline
\end{tabular}


provided by EM systems (e.g., Balasubramaniam et al. 2008, p. 54). Consequently, the assimilation of EM platforms could lead to far-reaching changes in the affected work processes, the distribution of tasks and existing responsibilities. These changes and benefits arise particularly from individual advantages on the operational level, which eventually lead to overall organizational changes and general economic benefits (e.g., Crupi and Warner 2008; Wulf and Jarke 2004). However, EMs are still an immature technology (de Vrieze et al. 2009, p. 69) which open up numerous research issues and problems that probably need to be addressed before widespread commercial usage becomes feasible. Therefore, the next subsections elaborate on potential economic benefits (Sect. 4.1), business application fields (Sect. 4.2) and challenges as well as further requirements (Sect. 4.3) of the Mashup technology in companies.

\subsection{Economic Benefits}

EMs can be regarded as promising platforms which can be deployed to increase business agility by improving business process flexibility and innovation to meet changing business demands. In the following, we emphasize the operational ability of sensing environmental changes and responding to them in a timely manner (Sambamurthy et al. 2003). The provision of on-demand access to data, services and functionality facilitates agile and flexible reactions to environmental changes.

One major driver of an increased need for operational business agility is the gap between employees' business needs and the limited resources of IT departments to meet those needs (Simmen et al. 2008, p. 1171). In many cases, an occurring demand of situational applications cannot be fully met by IT departments (Siebeck et al. 2009, p. 1). As a result, a so-called "long tail" arises which is defined by the fact that many specific, dynamic and heterogeneous user requirements are not covered by the standard solutions provided (Ketter et al. 2009, p. 294).

Figure 2 depicts this economic principle which is transferred from the niche strategy of selling a large number of unique items in relatively small quantities (Anderson 2006) to the demand scenario of business applications. The resulting long tail of individual and situational solutions required by business

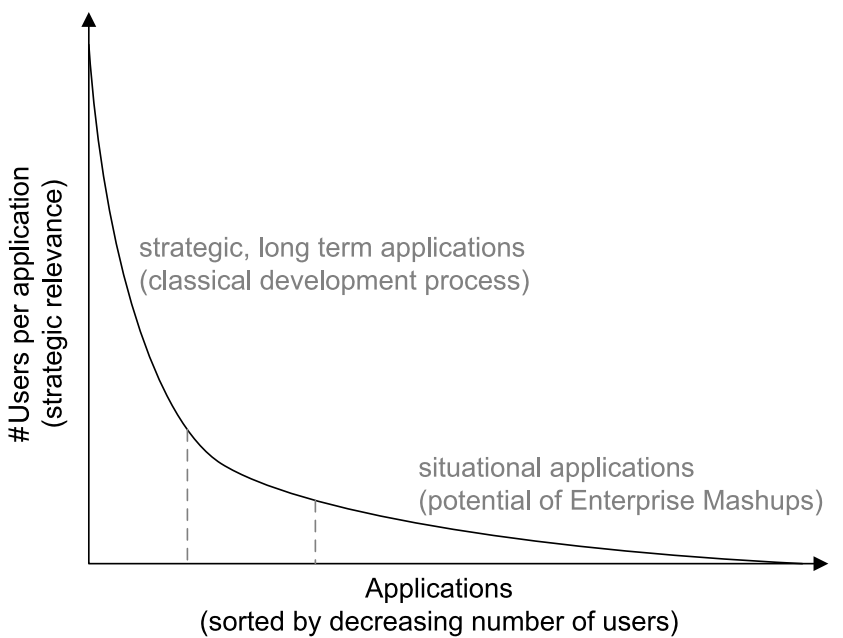

Fig. 2 Long tail of demanded applications (based on Carrier et al. 2008, p. 4; Siebeck et al. 2009, p. 2)

users is often not fully supported or even not implemented at all by traditional development approaches (Cherbakov et al. 2007, p. 748). The required high level of customization to build small personalized applications makes those applications labor intensive and therefore expensive (Carrier et al. 2008, p. 4).

In order to meet these requirements and challenges of operational agility, new development approaches based on lightweight composition and orchestration principles as well as easy UI integration are needed to incorporate the group of non-technical business users into the development process (Cherbakov et al. 2007, p. 4). In particular, the deployment of EM platforms seems to adequately fulfill the individual and heterogeneous requirements of business users by further integrating them. EMs represent a promising technology in order to efficiently address the aforementioned "long tail" of requirements to realize costeffects and efficiency gains and to overcome the traditional problems between IT department and business units (low reaction time or high expenses for an adequate IT-governance) (Wulf and Jarke 2004). Therefore, EMs can be viewed as a promising technology supporting dynamic rearrangements and reconfigurations of individual working processes. In essence, the introduction and deployment of EM environments could lead to several economic benefits in companies (e.g., Crupi and Warner 2008; Ketter et al. 2009) such as:

- Increased business agility, flexibility, and innovation to meet changing business demands
- Problem mitigation between the IT department and business units with regard to poor quality of support, low reaction time, and high cost of adequate IT governance

- Cost reduction by means of higher resource utilization and reusability, as well as lower IT operating and development costs

\subsection{Business Application Fields}

Grounded in the separation of functionality and dynamic combination of information from different sources, EM systems provide new means of designing distributed applications emphasizing on fields, such as, BI and BPM.

\subsubsection{Enterprise Mashups for Decision Support}

Due to the expanded use of Enterprise Resource Planning systems today, many companies store and disseminate vast amounts of transactional data (Holsapple and Sena 2005, p. 575). In this context, the role of BI is to identify, extract, and present the data considered of core importance to the business as additional support for managerial decisions. Consistent with the widely accepted definition by Vitt et al. (2002, p. 13), the term "Business Intelligence" describes a broad range of technologies, software platforms, specific applications, processes providing access to and analyzing data to improve the decision making process in an enterprise context.

The prevailing BI solutions often only provide a static UI, encompassing parameter-based reports, semi-free 
forms, ad-hoc reports and dashboardtype components (Kobielus et al. 2009, pp. 2-3). With respect to commercial utilization, the depicted solutions exhibit a high scalability and are especially suitable for long term strategic application. However, there are many existing information needs that are currently not well served by these systems, e.g., the need for customized, contextual information and real time decision support (Simmen et al. 2008 , p. 1171). One consequence is an extended queue of user requests to develop and revise reports, dashboards, cubes, and other analytical applications and data structures that are required for decision making (Kobielus et al. 2009, p. 4).

The emergence of "web as a platform" and the promotion of semantic web standards (e.g., XML, RSS, etc.) enable business users to compose different data sources and information services. In this context, Balasubramaniam et al. (2008, p. 51) state: "It's as if data has been liberated from the confines of the IT department". Therefore, an alternative solution in the BI context is to leverage the ideas of Web 2.0 and thus efficiently create modern interfaces that allow users to understand, use, and participate in the information creation process. These selfservice capabilities, provided by Mashup platforms, could reduce the pressure on the IT department by empowering employees to partially handle BI-related development tasks on their own by integrating different information services.

Another impacting force of EM assimilation in the BI context is the augmentation of information derived from unstructured data (Baars and Kemper 2008) that are either unavailable when required or even not available at all. Rooted in the tradition of management support systems, BI applications usually provide various ways of "structured data" analysis (Baars and Kemper 2008, p. 132) but still lack the functionality to analyze unstructured data (Negash 2004, p. 180). Since numerous business critical information sources (such as customer e-mail, web pages) are semi-structured or unstructured, corresponding means of data analysis are becoming increasingly important. Consistent with Jhingran (2006, p. 4), information Mashup platforms could potentially close the gap to enable simultaneous access to both structured and unstructured data. Business users can utilize the EM technology to get a better overview by combining various structured and unstructured data sources and using services relying on lightweight service models that are easily expandable via web technology (Simmen et al. 2008, p. 1171; Jhingran 2006).

In summary, EM platforms could be used to realize the "BI for the masses" concept (Negash 2004, p. 182) which is about providing reporting and analysis capability on all organizational levels.

\subsubsection{Workflow Collaboration}

Mashup technology encompasses flexible process methodologies and an application platform that can be leveraged to coordinate different services by allowing the individual users to align orchestration events along the business processes (de Vrieze et al. 2009). Crupi and Warner (2008, p. 1) state that Mashups "bring SOA to the people". Therefore, EM platforms could be employed to provide process integration of services and business process actors. In essence, a Mashup system eventually allows users to specify business process execution and enables the integration of process actors represented by both technical and humanrelated services. Finally, EMs can be utilized to trigger these business actors at corresponding process stages.

In contrast to traditional enterprisewide workflow management systems which are primarily used for the longterm process management of businesswide and strategic processes, Mashups focus on limited, flexible and situational work processes (de Vrieze et al. 2009, p. 69). Workflow management, by means of Mashup application, is rather focused on individual needs and workflows. Therefore, EM utilization can be considered to be the next step towards decentralized workflow management by knowledge workers.

The implementation of such work process collaboration platforms has to support the distribution and access to generated Mashup applications and the inclusion of different process actors. Furthermore, reusable process fragments have to follow the leading concept of modularity (de Vrieze et al. 2009, pp. 69-70).

\subsection{Challenges and Further Requirements}

In contrast to off-the-shelf software, which can be centrally administered, the EM infrastructure is managed by the business user with the IT department only taking a supporting role (Bitzer and Schumann 2009, p. 290; Hoyer and
Stanoevska-Slabeva 2009b, p. 8). This can lead to typical problems of decentralization such as the dependence on external service providers, lack of service quality, and uncontrolled use. Furthermore, EMs are still an immature technology. Widely accepted standards for effective component and EM discovery as well as their provisioning and the visual composition are still missing in existing EM environments (de Vrieze et al. 2009, p. 69; Hoyer and StanoevskaSlabeva 2009b, p. 10). Therefore, these organizational challenges and technical properties which are a prerequisite for the further acceptance of Mashup systems in a business environment are discussed.

\subsubsection{Governance Practices}

Even though EMs offer a lot of freedom for the end user, in a professional environment it is necessary to guide and control the use with governance practices. Uncontrolled development of EM applications might create problems such as redundancy, legacy, and maintenance costs. Therefore, new forms of intermediaries and specific design templates, version controls, and monitoring structures are required which improve the transparency, security and quality (Hoyer and Stanoevska-Slabeva 2009b, p. 12). Only then EMs as a means for situational applications and SOA can complement one another and provide a fast way for merging and representing internal and external resources from different sources (Bitzer and Schumann 2009, p. 8; Koschmider et al. 2009, p. 3). Hoyer and Stanoevska-Slabeva (2009b) propose a reference model for EMs which provides a foundation to define and to analyze EMs environments from a managerial and collaborative perspective. However, a comprehensive governance framework for a decentralized and user-friendly EM development from internal and external IT systems is still missing.

\subsubsection{Quality of Service}

One of the major risks in creating EMs is the dependency on external service providers. Therefore, the terms of service agreements should be investigated before a dependency is created. The complex and dynamic environment of service ecosystems imposes new requirements on a more holistic quality management, since so far, current approaches only focus on the technical aspects of quality (Riedl et al. 2008; Raza et al. 2008). 
Understanding which factors determine or influence the quality of Mashup components represents the first step toward valuable EM applications. The adaptability and dynamics that characterize the Mashup ecosystem require a separate and focused analysis. Cappiello et al. (2009) discuss the quality of Mashups based on a component-driven approach. They recognize the validity of consolidated models and metrics for the component-internal quality. In order to specify the quality, they consider Mashup components and their APIs and UIs in an isolated fashion and identify individual features (e.g., documentation, ease of use of the API and UIs, content provided through the API) that are likely to contribute to the success of a component.

For underlying sources and services that are not under the internal control of the enterprise in particular, aspects like QoS and fault tolerance are of high importance. In practice, the concept of service level agreements (SLA) should be used to address these aspects. An SLA creates a contract between the business user and a service provider or mediator ensuring a specific level of QoS as well as price and license models. The QoS provided might be measured by different key indicators such as availability (uptime), response time (delay) or security standards. Koschmider et al. (2009, p. 4) suggest another instrument to identify and ensure the quality of a service or component: the introduction of a trust certificate service. The owner of such a directory service can issue a license that certifies a service or an entire Mashup application. Similar to trust certificates for online shopping it is imaginable that Mashup owners would grant a license to the owner of the directory service. Positive certification would enable the Mashup owner to assure business users of the trustworthiness of the content and also the integrity of the implemented services and the whole Mashup application.

\subsubsection{Uncontrolled Use and Security Challenges}

In order to realize the key principles and business benefits of Mashup applications (see Sect. 3) Mashup platforms should be developed in an open environment that supports web-enabled service orientation (Balasubramaniam et al. 2008, p. 54). As a consequence, problems of uncontrolled consumption, caused by the realization of the business user participation approach could occur. Therefore, use issues and corresponding politics should be defined and instanced in a governance process.

Furthermore, technical security challenges have been identified as a critical aspect within the context of uncontrolled use (e.g., Lawton 2007; Barth et al. 2009). The security requirements regarding authentication, authorization, and access control (such as the single sign-on concept) are the same as for classical portal systems (de Vrieze et al. 2009, pp. 69-70). However, due to the fact that Mashup applications are usually based on a weboriented platform and therefore access both intra- and inter-organizational services and data sources, which usually lie beyond the IT-secure mechanisms (e.g., firewalls), safe and encrypted communication channels are particularly important (Lawton 2007). Additional security challenges arise if Mashup applications contain confidential information or if security logins are required to get access to particular resources. This necessitates technical mechanisms to control user connection and data security (e.g., Jackson and Wang 2007).

\subsubsection{Effective Discovery and Provisioning of Components and Enterprise Mashups}

Another important aspect and technical challenge is the prevailing heterogeneity among EMs (de Vrieze et al. 2009, p. 69; Maraika et al. 2008). Data resources and services can present a broader form of heterogeneity of semantics (I/O), functionality (behavioral), non-functionality (QoS, policy), and execution (runtime, infrastructure, exceptions). Therefore, mechanisms, such as a searchable shared service and data source repository are needed to provide users with easy access to the required resources and components. These discovery mechanisms should exhibit not only easy accessibility but also support the contextually appropriate discovery of relevant EM components (Braga et al. 2008). Issues such as licensing agreements, the period of validity, payment methods, and copyrights have to be considered and appropriate standards have to be defined and implemented (Cusumano 2007). Furthermore, the establishment of mechanisms and market platforms is required to allow business users to share their built EMs with other users, thus further facilitating the reuse of pre-built
EMs. Challenges that have to be met in this context are user-friendly access to EMs, efficient search functionalities and lightweight formats that enable simple reuse of EM applications, even for nonprogrammers (Balasubramaniam et al. 2008, p. 54).

\section{Conclusion}

This paper gives a state of the art overview of EM systems and their business potentials as well as challenges in an enterprise environment. In an extensive literature review we identified papers which deal primarily with the topic of EMs and categorized them according to their objectives and applied methodology. The results of the literature review confirm that extant scientific as well as practitioners' literature has primarily focused on technical concepts and the design of Mashup systems, drawing, for instance, on the design science paradigm (Hevner et al. 2004). However, a broader application of reference models for EM environment development and its verification according to the design science methodology is still outstanding and calls for further research. Therefore, future research should elaborate on appropriate technical infrastructure and the overall design and development of EM environments which covers the design principles discussed in this paper. In order to guarantee an efficient allocation of the underlying information or functionality resources as well as EM applications the design and development of an EM interaction and marketplace model is also an important field of research.

Despite this technically oriented research, further effort should be spent on an in-depth investigation of the organizational and individual impact of EM system deployment. In this sense, future scientific work will have to empirically analyze the impact of corresponding technologies on individual work processes, business processes, organizational structures, and the overall business outcome. Since little empirical (qualitative and quantitative) research has been accomplished in this field so far, a starting point would be the development of a common model to provide a contribution to the knowledge base on assimilation of Enterprise 2.0 technologies. With regard to the status quo described in this paper, several research opportunities to 


\section{Abstract \\ Immanuel Pahlke, Roman Beck, Martin Wolf \\ Enterprise Mashup Systems as Platform for Situational Applications}

\section{Benefits and Challenges in the Business Domain}

Currently, several Enterprise 2.0 platforms are beginning to emerge. This paper introduces Enterprise Mashup technology as a means to improve IT alignment of individual work processes and changing business needs. Enterprise Mashups enable users to create customized applications to easily find and transform business information and functionalities, as well as collaboratively share pre-built Mashup applications. Therefore, the concept of Enterprise Mashups integrates Web 2.0 technologies and principles with wellestablished paradigms such as Enterprise Information Integration, Business Intelligence, and Business Process Management. Involved organizational key drivers, technical challenges and inhibitors are discussed to assess the potential business value and explain the emerging expansion of Mashup platforms in companies.

Keywords: Enterprise Mashups, Business Agility, Enterprise Integration Infrastructure, Business Intelligence further understand the influences of EM technologies and related theoretical implications present themselves. This includes the identification and quantification of drivers and inhibitors, e.g., by conducting case and field studies within EM-adopting organizations to derive new insights.

Furthermore, it would be desirable to evaluate and extend existing organizational theories in order to explain why EM can result in a wide variety of outcomes on an organizational and individual level. It is expected that the decentralization process, granting more autonomy to the individual and his or her working environment in enterprises, will continue in the future with more and more companies adopting EM platforms or similar Enterprise 2.0 technologies (Young et al. 2008) in order to benefit from the improved interaction and support of knowledge workers. The active participation and integration of users in the knowledge creation process will probably lead to considerable change in organizational structures.

\section{Acknowledgement}

This work was developed as part of a research project of the E-Finance Lab at Goethe University Frankfurt. Any opinions, findings, conclusions, or recommendations expressed in this paper are those of the authors and do not necessarily reflect the views of the E-Finance Lab or its supporting partners. The authors are indebted to the participating universities and gratefully acknowledge the financial support of their industry partners.

\section{References}

Anderson C (2006) The long tail: why the future of business is selling less of more. Hyperion, New York

Baars H, Kemper HG (2008) Management support with structured and unstructured data - an integrated business intelligence framework. Inform Syst Manage 25(2):132148

Balasubramaniam $S$, Lewis GA, Simanta $S$, Smith DB (2008) Situated software: concepts motivation, technology, and the future. IEEE Softw 25(6):50-55

Barth A, Jackson C, Mitchell JC (2009) Securing frame communication in browsers. Commun ACM 52(6):83-91

Benkler Y (2006) The wealth of networks. How social production transforms markets and freedom. Yale University, London
Bitzer S, Schumann M (2009) Mashups: an approach to overcoming the business/IT gap in service-oriented architectures. In: Proceedings of the 15th Americas conference on information systems, San Francisco

Blake MB (2009) Knowledge discovery in services. IEEE Internet Comput 13(2):88-91

Blau B, Michalk W, Neumann D, Weinhardt C (2008) Provisioning of service mashup topologies. In: Proceedings of the 16th European conference on information systems, Galway

Borissov N, Brunner R, Neumann D, Freitag F, Navarro L, Weinhardt C (2009) Fostering efficiency of computational resource allocation -integrating information services into markets. In: Proceedings of the 17th European conference on information systems, Verona

Braga D, Ceri S, Daniel F, Martinenghi D (2008) Mashing up search services. IEEE Internet Comput 12(5):16-23

Cappiello C, Daniel F, Matera M (2009) A quality model for mashup components. In: Proceedings of the 9th international conference on web engineering, San Sebastián

Carrier N, Deutsch T, Gruber C, Heid H, Jarrett LL (2008) The business case for enterprise mashups. Web 2.0 technology solutions. IBM Whitepaper

Cherbakov L, Bravery A, Goodman BD, Pandya A, Baggett J (2007) Changing the corporate it development model: tapping the power of grassroots computing. IBM Syst J 46(4):743-762

Crupi J, Warner C (2008) Enterprise mashups part I: Bringing SOA to the people. SOA Magazine 18(5)

Cusumano MA (2007) The changing labyrinth of software pricing. Commun ACM 50(7):19-22

Daniel F, Matera M (2009) Turning web applications into mashup components: issues, models, and solutions. In: Proceedings of the 9th international conference on web engineering, San Sebastián. LNCS, vol 5648, pp 45-60

Daniel F, Yu J, Benatallah B, Casati F, Matera $M$, Saint-Paul R (2007) Understanding UI integration: a survey of problems technologies, and opportunities. IEEE Internet Comput 11(3):59-66

de Vrieze P, Xu L, Bouguettaya A, Yang J, Chen J (2009) Process-oriented enterprise mashups. In: Proceedings of the 4th international conference on grid and pervasive computing, Geneva

Duvall P, Matyas S, Glover A (2007) Continuous integration: improving software quality and reducing risk. Addison-Wesley, Reading

Gamble MT, Gamble R (2008) Monoliths to mashups. IEEE Softw 25(6):71-79

Gartner (2008) Top 10 Strategic technologies for 2009. Gartner symposium/ITxpo, October 12-16, Orlando. http://www. gartner.com/it/page.jsp?id=777212. Accessed 2009-07-20

Gurram R, Mo B, Gueldemeister R (2008) A web based mashup platform for enterprise 2.0. In: Proceedings of the 2008 international workshops on web information systems engineering, Auckland. LNCS, vol 5176, pp 144-151

Hevner AR, March ST, Park J, Ram S (2004) Design science in information systems research. MIS Quart 28(1):75-105

High R, Krishnan G, Sanchez M (2008) Creating and maintaining coherency in loosely coupled systems. IBM Syst J 47(3):357-376 
Holsapple CW, Sena MP (2005) ERP plans and decision-support benefits. Decision Support Systems 38(4):575-590

Hoyer V, Fischer M (2008) Market overview of enterprise mashup tools. In: Proceedings of the 6th international conference on service-oriented computing, Sydney. LNCS, vol 5364, pp 708-721

Hoyer V, Stanoevska-Slabeva K (2009a) Generic business model types for enterprise mashup intermediaries. In: Proceedings of the 15th Americas conference on information systems, San Francisco

Hoyer V, Stanoevska-Slabeva K (2009b) Towards a reference model for grassroots enterprise mashup environments. In: Proceedings of the 17th European conference on information systems, Verona

Hoyer V, Stanoevska-Slabeva K, Janner T, Schroth C (2008) Enterprise mashups: design principles towards the long tail of user needs. In: Proceedings of the 6th international conference on services computing, Honolulu

Jackson C, Wang HJ (2007) Subspace: secure cross-domain communication for web mashups. In: Proceedings of the 16th international conference on WWW, Banff

Janner T, Siebeck R, Schroth C, Hoyer V (2009) Patterns for enterprise mashups in $\mathrm{B} 2 \mathrm{~B}$ collaborations to foster lightweight composition and end user development. In: Proceedings of the 7th international conference on web services, Washington

Jhingran A (2006) Enterprise information mashups: integrating information, simply. In: Proceedings of the 32nd international conference of very large databases, Seoul

Ketter W, Banjanin M, Guikers R, Kayser A (2009) Introducing an agile method for enterprise mash-up component development. In: Proceedings of the 12th IEEE conference on commerce and enterprise computing, Washington

Keyser C (2007) Composite applications - the new paradigm. The Architectural Journal 13:2-5

Kim DJ, Yue KB, Hall SP, Gates T (2009) Global diffusion of the internet XV. Commun AIS 24(38)

Klöckner S (2009) Fast access: a system architecture for restful business data. In: Proceedings of the 15th Americas conference on information systems, San Francisco

Kobielus JG, Karel R, Evelson B, Coit C (2009) Mighty mashups: do-it-yourself business intelligence for the new economy. Forrester Research 2009

Koschmider A, Torres V, Pelechano V (2009) Elucidating the mashup hype: definition, challenges, methodical guide and tools for mashups. In: Proceedings of the 2nd workshop on mashups, enterprise mashups and lightweight composition on the web, Madrid

Lawton G (2007) Web 2.0 creates security challenges. Computer 40(10):13-16

Lieberman H, Paterno F, Wulf V (2006) Enduser development. Springer, Dordrecht

Liu X, Hui Y, Sun W, Liang H (2007) Towards service composition based on mashup. In Proceedings of the 4th IEEE international conference on service computing, Chicago

Lizcano D, Soriano J, Reyes M, Hierro JJ (2008) EzWeb/FAST. In: Proceedings of the 10th international conference on information integration and web-based applications \& services, Linz

López J, Bellas F, Pan A, Montoto P (2009) A component-based approach for engineering enterprise mashups. In: Proceedings of the 9th international conference on web engineering, San Sebastián. LNCS, vol 5648, pp 30-44

Maraika Z, Lazovik A, Arbab F (2008) Building mashups for the enterprise with SABRE. In: Proceedings of the 6th international conference on service-oriented computing, Sydney. LNCS, vol 5364, pp 70-83

Maximilien EM, Ranabahu A, Gomadam $K$ (2008) An online platform for web APIs and service mashups. IEEE Internet Comput 12(5):32-43

Negash S (2004) Business intelligence. Commun AIS 13:77-195

Nestler T (2008) Towards a mashup-driven end-user programming of SOA-based applications. In: Proceedings of the 10th international conference on information integration and web-based applications and services, Linz

Raza M, Hussain KF, Chang E (2008) A methodology for quality-based mashup of data sources. In: Proceedings of the 10th international conference on information integration and web-based applications and services, Linz

Riedl C, Böhmann T, Rosemann M, Krcmar H (2008) Quality aspects in service ecosystems: areas for exploitation and exploration. In: Proceedings of the 10th international conference on electronic commerce, Innsbruck

Rosenberg F, Khalaf R, Duftler M, Curbera F, Austel P (2009) End-to-end security for enterprise mashups. In: Proceedings of the 7th international joint conference on service-oriented computing, Stockholm LNCS, vol 5900, pp 389-403

Sambamurthy V, Bharadwaj A, Grover V (2003) Shaping agility through digital options: reconceptualizing the role of information technology in contemporary firms. MIS Quart 27(2):237-263

Saunders C (2010) MIS Journal rankings. http://ais.affiniscape.com/displaycommon. $\mathrm{cfm}$ ?an $=1$ \&subarticlenbr $=432$. Accessed 2010-02-23

Schrader U, Hennig-Thurau T (2009) VHBJOURQUAL2. Business Research 2(2):180204

Schroth C, Christ O (2007) Brave new web: emerging design principles and technologies as enablers of a global SOA. In: Proceedings of the 4th IEEE international conference on service computing, Utah

Sheng QZ, Benatallah B, Maamar Z, Ngu $\mathrm{AH}$ (2009) Configurable composition and adaptive provisioning of web services. IEEE Trans Serv Comput 2(1):34-49

Siebeck R, Janner T, Schroth C, Hoyer V, Wörndl W, Urmetzer F (2009) Cloud-based enterprise mashup integration services for B2B scenarios. In: Proceedings of the 2nd workshop on mashups, enterprise mashups and lightweight composition on the web, Madrid

Simmen $D$, Altinel $M$, Markl V Padmanabhan S, Singh A (2008) Damia: data mashups for intranet applications. In: Proceedings of the 14th international conference on management of data, Vancouver

Soriano J, Lizcano D, Cañas MA, Reyes M, Hierro JJ (2007) Fostering innovation in a mashup-oriented enterprise 2.0 collaboration environment. Communications of SIWN 1(1):62-68

Surowiecki J (2004) The wisdom of crowds. Anchor Books, New York

Vancea A, Grossniklaus M Norrie MC (2008) Database-driven web mashups. In: Proceedings of the 8th international conference on web engineering, Washington

Vitt E, Luckevich M, Misner S (2002) Business intelligence: making better decisions faster. Microsoft, Washington

von Hippel E (2005) Democratizing innovation. MIT, Cambridge

Webster J, Watson RT (2002) Analyzing the past to prepare for the future: writing a literature review. MIS Quart 26(2):13-23

Westerski A (2009) Integrated environment for visual data-level mashup development. In: Proceedings of the 10th international conference on web information systems engineering, Poznan. LNCS, vol 5802, pp 481-487

Wulf V, Jarke M (2004) The economics of end user development. Commun ACM 47(9):41-42

Young OG, Daley E, Gualtieri M, Lo H, Ashour E (2008) The mashup opportunity-how to make money in the evolving mashup ecosystem? Forrester Research 2008

Yu J, Benatallah B, Casati F, Daniel F (2008) Understanding mashup development. IEEE Internet Comput 12:44-52 